\title{
Radiological Weapons: How Great Is The Danger?
}

G.M. Moore

June 1, 2003

U.S. Department of Energy

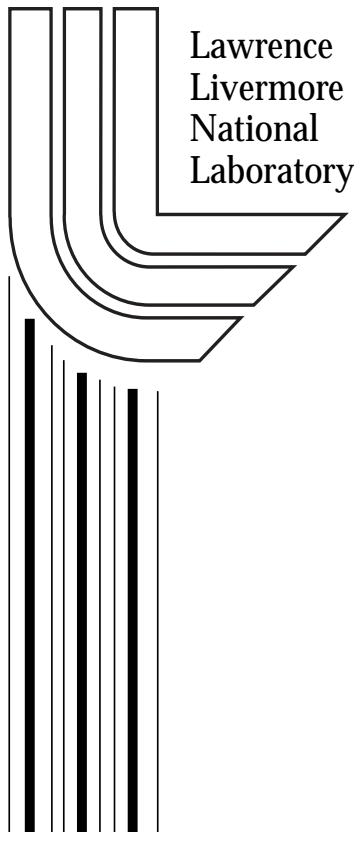




\section{DISCLAIMER}

This document was prepared as an account of work sponsored by an agency of the United States Government. Neither the United States Government nor the University of California nor any of their employees, makes any warranty, express or implied, or assumes any legal liability or responsibility for the accuracy, completeness, or usefulness of any information, apparatus, product, or process disclosed, or represents that its use would not infringe privately owned rights. Reference herein to any specific commercial product, process, or service by trade name, trademark, manufacturer, or otherwise, does not necessarily constitute or imply its endorsement, recommendation, or favoring by the United States Government or the University of California. The views and opinions of authors expressed herein do not necessarily state or reflect those of the United States Government or the University of California, and shall not be used for advertising or product endorsement purposes.

This work was performed under the auspices of the U. S. Department of Energy by the University of California, Lawrence Livermore National Laboratory under Contract No. W-7405-Eng-48.

This report has been reproduced directly from the best available copy.

Available electronically at http://www.doc.gov/bridge

Available for a processing fee to U.S. Department of Energy

And its contractors in paper from

U.S. Department of Energy

Office of Scientific and Technical Information

P.O. Box 62

Oak Ridge, TN 37831-0062

Telephone: (865) 576-8401

Facsimile: (865) 576-5728

E-mail: reports@adonis.osti.gov

Available for the sale to the public from

U.S. Department of Commerce

National Technical Information Service

5285 Port Royal Road

Springfield, VA 22161

Telephone: (800) 553-6847

Facsimile: (703) 605-6900

E-mail: orders@ntis.fedworld.gov

Online ordering: http://www.ntis.gov/ordering.htm

OR

Lawrence Livermore National Laboratory

Technical Information Department's Digital Library

http://www.llnl.gov/tid/Library.html 


\section{Contents}

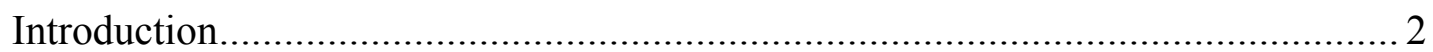

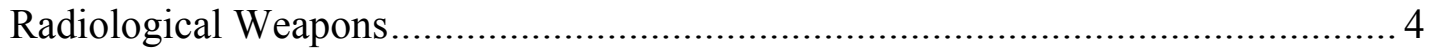

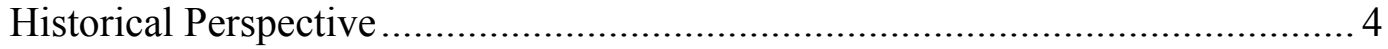

Technical Background ................................................................................ 5

Radioactive Materials .......................................................................... 5

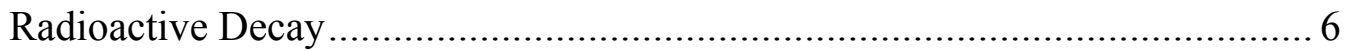

Dose And Health Effects ...................................................................... 7

External And Internal Doses ................................................................. 9

Radioactive Contamination........................................................... 10

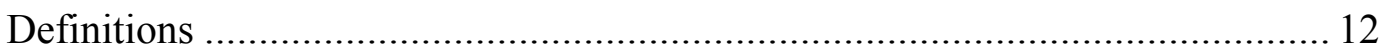

Existing Definitions ..................................................................... 12

Proposed Definition of Radiological Weapon ......................................... 13

Steps To Acquire And Use Radiological Weapons ........................................ 14

Radioactive Materials Available For Use In A Radiological Weapon ................ 15

Materials Found In Sources And Industrial Equipment ............................ 15

Materials Found In Reactors And Reactor Related Operations ..................... 20

Materials Found In Radioactive Material Disposal Sites ............................ 20

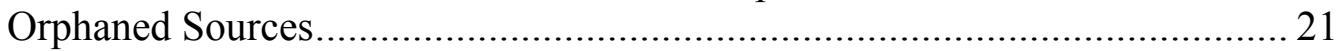

Depleted Uranium ........................................................................ 21

Domestic Security of Radioactive Materials ............................................... 21

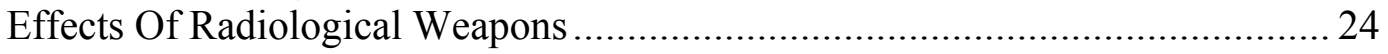

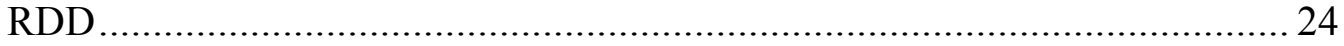

Reactor Or Fuel Storage Attack ......................................................... 27

Attack On A Disposal Site ..................................................................... 28

Intentional Irradiation Without Dispersal ................................................ 29

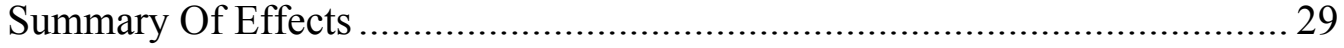

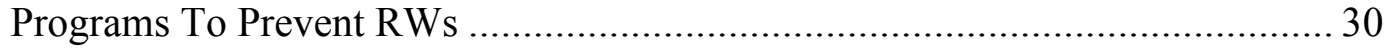

Programs To Minimize The Impact Of A Radiological Weapon ....................... 31

Medical Programs............................................................................. 31

Decontamination ............................................................................. 32

The Need For Pre-Event Planning For Economic Loss ............................. 32

The Impact Of The Suicidal Terrorist .................................................... 33

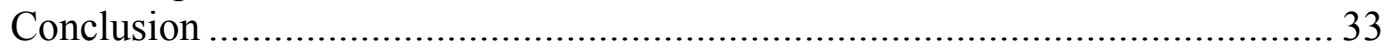

References............................................................ 36 


\title{
Radiological Weapons:
}

\section{How Great Is The Danger? ${ }^{1}$}

\author{
by George M. Moore
}

\section{Introduction}

President Eisenhower's Atoms for Peace speech in 1953 was greeted with worldwide anticipation of the benefits to mankind that would begin to flow from the peaceful use of the atom in multiple areas of technology. Although the release of nuclear technology under Atoms for Peace heightened concerns for the proliferation of nuclear-yield weapons, the feeling in 1953 was that the risks outweighed the benefits. For many years, this assessment of relative risks has been under review as proliferation concerns, driven by improvements in technology, have arguably made proliferation easier. However, it is only more recently that concerns about the nonproliferation uses of radioactive materials to injure persons or property have risen to the level of national and international debate. In contrast to the focus on national intentions in proliferation, these new concerns have focused primarily on the potential use of radioactive materials by terrorist or subnational groups.

Well before the September 11, 2001, attacks on the World Trade Center and the Pentagon, a significant concern existed that a terrorist group, or even a single individual, would use a radiological weapon $(\mathrm{RW})^{2}$ to attack people and property. September $11^{\text {th }}$ clearly increased those concerns. Attention since September 11 has focused primarily on radiological dispersal devices (RDDs) — devices designed to spread radioactive material. The expression "dirty bomb" entered the public awareness through numerous media stories and has, in the public mind, become synonymous with RDD even though under most definitions a "dirty bomb" is only one example of an RDD. In addition to mounting concerns about RDDs, there are now also heightened concerns about attacks on nuclear reactors, the spread of radioactive materials by non-explosive methods, and other uses of radioactive material to injure people and property.

Concerns about access to nuclear materials for malevolent purposes have prompted numerous domestic and international incentives to minimize risk to the population. For

\footnotetext{
1 * This paper represents only the opinions of the author. It does not represent the views of the Center for Global Security Research (CGSR), Lawrence Livermore National Laboratory (LLNL), the University of California, the Department of Energy (DOE), or any other department or agency of the U.S. Government.

${ }^{2}$ We define Radiological Weapon specifically infra in Section D. A brief working definition for this paper is that an RW is any device or scheme to use radioactive material to injure people or property.
} 
example, the International Atomic Energy Agency (IAEA) ${ }^{3}$ recently held a conference in Vienna in March 2003 on these issues. Participants from member states and invited organizations focused on major topics that included:

- Recovering and securing high-risk, poorly controlled radioactive sources.

- Strengthening long-term regulatory control of radiological sources.

- Stopping illicit trafficking/border controls.

- Planning the response to radiological emergencies arising from the malevolent use of radioactive sources. (IAEA Worldatom 2002)

How dangerous are RWs? Are RWs sufficiently dangerous to require regulations to severely curtail the availability and use of radioactive materials? Would restrictive regulations cause a rollback of many of the benefits that the widespread use of radioactive materials have brought to modern societies? Has Atoms for Peace created a world of unprecedented hazard, or can changes be made to deal with the threat of RWs while retaining the beneficial uses of radioactive materials?

One of the underlying purposes of this paper is to provoke thinking about the interplay between the regulation of radioactive materials and the risk of their use in an RW. Also considered in this paper are the types of RWs that a terrorist might use, the nature of the threat and danger posed by the various types of RWs, the essential elements that must be considered in responding to the terrorist use of an RW, and what steps may need to be taken a priori to minimize the consequences of the inevitable use of an RW. Because RDDs have been the focus of so much recent concern and because RDDs are arguably the most likely of RWs to be used by a terrorist group, a major focus of this paper will be on RDDs.

A brief history and a technical introduction will provide a framework for discussions of RWs. Because the definition of a problem may tend to bound problem resolution, it is important to review the various definitions of RWs currently used by various agencies. We will consider whether the definitions are adequate or whether they need to be modified to present the entire scope of the RW problem and encourage the "thinking outside the box" mentality that may be gained by an attempt to come to grips with the gestalt of RWs rather than consider piecemeal devices.

Finally, although as the IAEA conference illustrates that major efforts are underway to minimize the terrorists' ability to acquire and use RWs, this paper will address what programs and policies need to be considered under the assumption that a terrorist attack

\footnotetext{
${ }^{3}$ Created in 1957 as organization to carry out Atoms for Peace, the IAEA has provided international guidance for the peaceful utilization of nuclear materials under the auspices of the United Nations.
} 
using radioactive material will almost surely occur in the reasonably foreseeable future. ${ }^{4}$ Indeed, it can be argued that the apparent Chechen placement of a cesium 137 source in a Moscow park in 1995 was a first use of an RW.

\section{Radiological Weapons}

\section{Historical Perspective}

The concept of an RW - using radioactive material to injure - is not new. Even before the development of nuclear weapons and reactors, the harmful effects of the various types of radiation were known. Serious considerations about using radioactive materials to injure is generally a post-World War II (WWII) issue simply because significant quantities of radioactive materials did not become available until the post-WWII era.

Considerable thought was given to radiation as a weapon in the early Cold War era. Questions were immediately raised after Hiroshima and Nagasaki about whether armies and navies could maneuver on what some believed would be the atomic battlefield in future conflicts. Significant efforts were made to answer these questions and to understand the effects of nuclear weapons. The direct radiation effects from the detonation and the effects of radiation received from the radioactive material produced by the detonation and generally transported as fallout were studied extensively. This information was widely disseminated to the general public and became part of Civil Defense planning in the United States. (Glasstone and Dolan 1977). The converse of the military's interest about whether access could be gained to an area where radioactive material was present was whether access could be denied to an enemy by intentional dispersal of radioactive materials. Apparently each nation that has considered area denial has come to the same conclusion: that dispersal has little military value. Thus, it appears that no nation has ever seriously developed radioactive material dispersal devices as part of its military stockpile.

In contrast to the prereactor era when the only radioactive materials available were the infrequent materials found in nature or minute quantities made in an accelerator, we now live in a world where radioactive materials are omnipresent, ${ }^{6}$ even in what would be considered very underdeveloped countries. Nations' abilities to regulate and deal with radioactive materials vary over a broad spectrum. Most governments have agencies

\footnotetext{
${ }^{4}$ A recent British analysis put the probability of such an event in the UK at 10 to $40 \%$ within the next 5 years. "Dirty Bombs: Threat And Response," Jane's Terrorism \& Security Monitor, February 01, 2003.

${ }^{5}$ This widely reported event occurred in November 1995. A Chechen rebel commander told a Russian television station where a buried container of radioactive cesium could be found. See, e.g. "Russia Says Chechens a Nuclear Threat to U.S. Military," Agence France -Presse, January 30, 2003.

${ }^{6}$ In the United States there are about 2 million devices containing radioactive sources, excluding those licensed directly by states and those used by the Department of Energy. Presentation by Richard A. Meserve, Chairman U.S. Nuclear Regulatory Commission at the IAEA Conference Buenos Aires, Argentina, December 11, 2000.
} 
whose purpose is to regulate radioactive materials and to protect the public in the event of an accidental dispersal of the material. The umbrella of the IAEA support is routinely given to less capable nations.

In many countries, the military has the greatest ability to deal with radioactive material. Even militaries of countries that do not have nuclear weapons have developed and maintained the ability to survive on the nuclear battlefield and have developed systems to detect radiation and to protect their forces and populations from the effects of nuclear weapons and radioactive materials. Many countries also have the ability to decontaminate areas that become contaminated with dangerous levels of radioactive materials due to military or civilian activities.

\section{Technical Background}

To understand the dangers of RWs, it is necessary to initially consider some elementary aspects of radiation, radioactive decay, dose, and the health effects of exposure to radiation. Perhaps three fundamental concepts and a few simple related equations can provide a solid foundation for discussions of RWs (Shapiro 2002).

\section{Radioactive Materials}

Radioactive materials are those materials that decay over time. In their decay, they may emit alpha particles, beta particles, $x$ rays, gamma rays, or neutrons or some combination of either particles or electromagnetic radiations.

Some radioactive materials occur in nature, and some are manmade. The discovery of radioactivity and the early experiments with radiation were all done with natural ores or with radioactive elements chemically concentrated from natural deposits. For example, radium $226^{7}$ was one of the first recognized radioactive materials. Curie obtained radium 226 by chemical concentration. Man's ability to create $\mathrm{x}$ rays preceded the discovery of radioactive materials, but the ability to create significant amounts of radioactive materials only followed the development of the nuclear reactor.

Some naturally occurring radioactive materials are materials that have existed since before the formation of the Earth. ${ }^{8}$ These radioactive materials have half-lives ${ }^{9}$ that are so long relative to the age of the Earth that they still exist in nature. For example, potassium 40 has a half-life is on the order of a billion years. Other naturally occurring radioactive materials have shorter half-lives, but are present in nature because they are part of the decay chain of a longer-lived radioactive precursor. For example, Curie's radium 226 has

\footnotetext{
${ }^{7}$ Specific radioisotopes, such as radium 226 , will be referred to in this paper by the name of their chemical element (radium) and by the total number of nucleons (protons plus neutrons) in the nucleus. This information may also be presented in a form using the nucleon superscript and chemical symbol for the element such as ${ }^{226} \mathrm{Ra}$ for radium 226.

${ }^{8}$ Leading to Carl Sagan's famous statement that humans are made from the material of long-dead stars.

${ }^{9}$ The half-life of a radioactive material is the time it takes for one-half of the material initially present to decay. Radioactive decay will be discussed more fully in the following section.
} 
a half-life of about 1600 years but is part of the decay chain of uranium 238 whose halflife is about 4.5 billion years. It should be noted that some natural radioactive ores, even without concentration, are sufficiently radioactive that under current environmental regulations they can be legally purchased but would require cleanup if distributed in populated areas.

Whether radioactive materials are naturally occurring or manmade, they follow the same decay principles discussed in the following section.

\section{Radioactive Decay}

Elements are defined and named based on the number of protons in the nucleus. For an electrically neutral atom, the number of negatively charged electrons balances the number of positively charged protons in the nucleus. Addition or subtraction of orbiting electrons gives rise to negative or positive ions respectively. Nuclei with the same number of protons but with different numbers of neutrons are isotopes of the element. Some elements occur in nature with only one stable nuclear structure, but others have numbers of stable structures or isotopes.

On a nuclear level, radioactive elements decay on a purely random basis, ${ }^{10}$ but, because even a small fraction of a gram of any material contains a phenomenally large number of nuclei, ${ }^{11}$ the overall radioactive decay of a radioactive material is well behaved and displays a characteristic half-life. ${ }^{12}$ Each radioactive isotope decays in an exponential manner, and the amount of the isotope $(\mathrm{N})$ remaining after an interval of length $t$ where $t$ was zero at the beginning of the interval is given by:

$$
N(t)=N(t=0) e^{-(.693 / T 1 / 2) x t}
$$

where $t$ is the length of the interval and $T_{1 / 2}$ is the half-life of the isotope measured in the same units as the interval. Thus, after 8 half-lives $\left(t=8 \times T_{1 / 2}\right)$ only about $1 / 3,000$ of the original material remains.

A convention used to discuss radioactive decay is the specific activity $(\alpha)$ of a radioactive material. Activity is the amount of material decaying per second and is described in units of Becquerels, ${ }^{13}$ or in the older unit of Curies. ${ }^{14}$ Activity relates to the mass of the material present and to its half-life. For a number of nuclei present at time $t, N(t)$, the specific activity, $\alpha(t)$ of a radioactive isotope is given by:

\footnotetext{
${ }^{10}$ If we could sit and watch an individual nucleus, the probability that it would decay in any given small time increment would be a constant.

${ }^{11}$ For an isotope with an atomic weight of $\mathrm{x}$, $\mathrm{x}$ grams of that material contains $6.02 \times 10^{23}$ nuclei. For example, 4 grams of helium contains $6.02 \times 10^{23}$ helium nuclei.

${ }^{12}$ The half-life of a radioactive material is the length of the time interval in which half of the material present at the beginning of the interval will decay.

${ }^{13}$ One Bequerel $(\mathrm{Bq})$ is one decay per second.

${ }^{14}$ One Curie is $3.7 \times 10^{10}$ decays per second, or $37 \mathrm{GBq}$.
} 


$$
\text { Activity }=\alpha(\mathrm{t})=\lambda \times \mathrm{N}(\mathrm{t})
$$

where $\lambda$ is a constant $=\left(.693 / \mathrm{T}_{1 / 2}\right)$.

The obvious result of equations 1 and 2 is that radioactive materials with short half-lives (such as many medically useful isotopes) decay away rapidly and are therefore probably not well suited for radiological weapons. Equation 2 shows that, for a given level of activity, the half-life and amount of material are inversely related, so a greater amount of material of a longer half-life is needed to produce the same activity produced by a material of shorter half-life.

When radioactive materials decay, the resulting particles and/or electromagnetic radiations have various energies. The effect of these decay products is considered in the following section.

\section{Dose And Health Effects}

Particle or electromagnetic radiation from radioactive material can directly ionize or induce ionization in material. The majority of interactions with matter that the particles or electromagnetic radiation passes through (e.g., shielding, air, and people) are with the orbital electrons of that material. Some of the interactions knock electrons out of their orbits, creating ions. Particles and electromagnetic radiation capable of creating ions are described as ionizing radiation in contrast to non-ionizing radiation such as radio- and microwaves, which interact with matter without creating ions.

The key factor in determining the damage done by ionizing radiation is the energy deposited in the material through which the radiation passes (air, lead shielding, or a person, ), a value that can be measured. Although the energy deposition for particles and photons is non-linear, it is convenient to consider bulk material properties and averages when dealing with gross medical effects. The unit of measurement for energy deposition in what has become known as the "traditional measurement system" is the rad. ${ }^{15}$ Because different types of radiation have different abilities to damage the human body, the energy deposition in rads is adjusted by a weighting factor, the Relative Biological Effectiveness (RBE) that is defined for each type of radiation. ${ }^{16}$ The multiplication of the dose in rads times the RBE equals the dose in Roentgen Equivalent Man (rem). ${ }^{17}$ Throughout this paper, we will use the traditional units to describe dose and effects.

\footnotetext{
${ }^{15}$ The rad is defined as 100 ergs of energy deposited per gram. The newer SI unit for absorption is the Gray (Gy), which is defined as 1 Joule per kilogram or $6.24 \times 10^{9} \mathrm{MeV} / \mathrm{g}$. Thus $100 \mathrm{rads}=1 \mathrm{~Gy}$.

${ }^{16} \mathrm{RBE}=1$ for beta and gamma radiation, 20 for alpha particles and neutrons (RBE for neutrons is defined as 10 by the Nuclear Regulatory Commission (NRC) and 20 by the International Council on Radiation Protection (ICRP). The RBE has become a dated concept as responses of individual organs have become better known, and RBE has been replaced by organ-specific weighting. For general overall understanding, however, RBE is still a useful concept.

${ }^{17}$ The SI equivalent of the rem is the Sievert (Sv) where Sv = Gray x (an energy-dependent weighting factor $\mathrm{w}_{\mathrm{r}}$ ) where $\mathrm{w}_{\mathrm{r}}$ is conceptually related to RBE, but is a more specific energy and organ-specific quantity. Thus $100 \mathrm{rem}=1 \mathrm{~Sv}$. When one considers centi Sieverts (cSv) and centi Grays (cGy), one finds these are exactly equivalent to rems and rads, respectively.
} 
Almost since the discovery of radioactivity, man has been aware that ionizing radiation can cause injury and can induce cancers of various sorts. Understanding the medical effects increased during the 1940s and 1950s with analysis of the effects of the use of nuclear weapons and several nuclear accidents. The reader with an interest in medical effects can refer to any of a number of medical or health physics texts on the issue.

For an understanding of the danger of RWs, the relationships between dose and medical consequences need to be understood. There is, of course, a temporal quality to the body's reaction to receiving a given amount of radiation. The same total dose administered over months to an organism will probably have less effect than if the dose was received within a few minutes. It is generally accepted that a whole body ${ }^{18}$ dose of somewhere in the neighborhood of 400 to 500 rem is an LD50 dose, a dose that will prove lethal to about $50 \%$ of a population exposed at that level.

Although the medical consequences of high-level doses of radiation are relatively well known, the medical consequences of low-level doses (those doses on the order of background radiation or several times the dose rate of background radiation) are unknown, and perhaps unknowable, since the effects are so infrequent that they cannot be distinguished with statistical significance from random fluctuations of background rates of the consequence in order to establish a cause and effect correlation. Since the consequences of low-level exposure are not known, for regulatory purposes it is assumed that high-dose effects can be linearly extrapolated to the low-dose region. This assumption is the basis of the Linear No Threshold (LNT) regulation. Under LNT if an average dose of 100 rem will produce a consequence at a rate of $x$ per 100,000 in the exposed population, an average dose of $1 \mathrm{rem}$ will produce the same effect at a rate of $\mathrm{x} / 100$ per 100,000 in the exposed population.

Whatever the health effect of a given dose might be, we need to be able to calculate or approximate the dose. How does the dose received relate to the activity of a specific radioactive isotope? Some general rules-of-thumb may be useful in helping to understand the relationship between activity and dose and aid in determining the dangers associated with RWs.

It is useful in order to gain an understanding of dose to consider the dose resulting from a point source. ${ }^{19}$ The dose received by an individual from an unshielded point source of radiation can be related to the activity and energy of the decay by the rule-of-thumb relationship for beta and gamma radiation:

$$
\text { Dose }(\text { in rem or } \mathrm{cSv} / \text { hour })=6 \mathrm{CE} / \mathrm{R}^{2}
$$

\footnotetext{
${ }^{18}$ Whole body dose is considered to be the dose of radiation received by the body in its entirety, as distinct from a dose to a limited area of the body.

${ }^{19}$ A point-source assumption is one in which all the radioactive material is considered to exist at a single point in space. Since most radioactive samples are very small, the point-source approximation is often fairly accurate.
} 
where $\mathrm{C}$ is the source strength in Curies, $\mathrm{E}$ is the energy of the decay in $\mathrm{MeV},{ }^{20}$ and $\mathrm{R}$ is the distance from the source in feet. An equivalent rule-of-thumb can be stated for activity in Bequerels and distance in meters as follows:

$$
\text { Dose }(\text { in rem or } \mathrm{cSv} / \text { hour })=0.015 \mathrm{GE} / \mathrm{M}^{2} \quad \text {, }
$$

where $\mathrm{G}$ is the source strength in GigaBq, $\mathrm{E}$ is the energy of the decay in $\mathrm{MeV}$, and $\mathrm{M}$ is the distance from the source in meters.

In addition to these rule-of-thumb equations, a very gross, but conservative and useful, rule-of-thumb is that a 1-Curie source gives a dose of $1 \mathrm{rem} / \mathrm{hr}$ at a distance of 1 meter.

In dealing with individual RWs, the type and energy of decay and the half-life of the materials involved are extremely important, but at the conceptual level we can engage in some generalizations. The equations and rules-of-thumb above are principally applicable to beta and gamma doses received by exposure to an external source.

\section{External And Internal Doses}

External doses come from radioactive materials outside the body. Internal doses come from radioactive materials that are ingested or inhaled or enter the body through wounds. RWs are capable of presenting either type of hazard depending on the radioactive material(s) and the type of dispersal.

Neutron and gamma emitters are both external and internal hazards. Some radioactive materials, however, present a negligible threat if they remain outside the body. Alpha radiation will not penetrate beyond the dead skin layers on the body's surface.

Radioactive materials that are primarily alpha emitters (such as ${ }^{238} \mathrm{U}$ ) are of concern only if inhaled or ingested. Beta particles penetrate more deeply than alpha particles, but are easily shielded against and typically do not penetrate very far beyond the outer skin layers. Thus, beta emitters are generally also more dangerous if they enter the body, but they can cause significant external damage if the energy of the decay is high and there is a significant dose deposited in the skin.

When radioactive material enters the body not only is the exposure to the body more intimate and direct, (i.e. organs may be affected that would not be reachable by an external dose) the material continually contributes a dose as long as it remains in the body. Radioactive materials that enter the body behave chemically exactly like nonradioactive material in the same physical form. Each element or compound will have a biological half-life. ${ }^{21}$ It is typical that a material will seek certain organs or structures in

\footnotetext{
${ }^{20} \mathrm{E}$ is the total energy associated with each decay. For example, $\mathrm{E}=.662$ for ${ }^{137} \mathrm{Cs}$, but for ${ }^{60} \mathrm{Co}$ it is about 2.5 , the sum of the two principal gamma emissions in each ${ }^{60} \mathrm{Co}$ decay.

${ }^{21}$ Biological half-life is analogous to the radioactive half-life. The biological half-life is a measure of how long it takes the body to eliminate half of the material present at the time observation began. Equation 1 can be used for calculating the amount remaining in the body as a function of time using the biological half-life instead of the radioactive half-life.
} 
the body and thus the dose to specific organs may be significantly higher than if the material spread uniformly throughout the body.

One of the principal ways that radioactive materials enter the body is through inhalation. Therefore inhalation of radioactive materials has received a significant amount of study. Beginning with nuclear weapons tests and the radioactive cloud following airbursts, there has been a significant amount of work done to determine what types of compounds and what particle sizes remain in the lungs. Given assumed rates of respiration, there are models that can predict the dose from inhalation exposure in a debris cloud.

Of particular interest in dealing with the results of RWs are methods that have been developed to remove radioactive materials from the body either by dilution or by flushing or washing materials from the body using chemical extraction techniques. There are also certain chemical compounds, such as potassium iodide, that can pre-load the body to minimize the uptake of certain radioactive materials.

\section{Radioactive Contamination}

When determining the effect of RWs, it is essential to consider the issue of contamination of people and property and the related issue of clean-up criteria. Both property and persons can be contaminated. Decontamination of people is generally considered as part of the medical response to a radiological incident and will be considered separately below. This section will consider contamination of property.

Radiation clean-up guidelines have been developed for dealing with accidents, spills, and such. These guidelines require cleaning areas and surfaces to near the background level. Are such clean-up guidelines realistic when dealing with a dispersal device? Western society has never had to deal with a Chernobyl-level incident where the economic solution to cleanup was to evacuate areas. When dealing with a dispersal of radiation by an RW, the interplay of dose, medical effects, and cleanup required need to be addressed since these directly affect the economic and social impact of an RW.

In the United States, the Environmental Protection Agency (EPA) monitors cleanup. Clean-up standards are set in 10 Code of Federal Regulations (CFR) Part 20. When the EPA considers a radioactively contaminated site, there may be specific clean-up guidelines for the various radioactive isotopes present at the site. There are a variety of clean-up standards depending on the type of area contaminated and type of radioactive material. . For example, there are large tables of allowable concentrations of various isotopes in drinking water. In this paper, however, we will only consider simplistic surface contamination since, in general, the dilution in water supplies, coupled with the insoluble character of most radioactive materials of interest, make contamination of water supplies a relatively ineffective method of dispersing radioactive material.

Contamination guidelines are related to the dose that may be received from the radioactive material, and the assessment of the risk associated with the dose is derived 
from the LNT model used to determine risks associated with radioactivity. ${ }^{22}$ There has been a long-standing debate about the appropriateness of the LNT assumption. Opponents of LNT cite evidence of radiation hormesis, and proponents consider it a prudent method of dealing with the unknown. Both proponents and opponents generally concede that the statistics of low-dose exposure prevent practical determination of whether there is any measurable effect for low-dose population exposures. ${ }^{23}$

To get some idea of the consequences of clean-up standards and how they relate to the dangers of RWs, it is interesting to do some very crude calculations. ${ }^{24}$ A general rule-ofthumb for determining contamination is that a surface is contaminated if the radioactive material on the surface exhibits an activity of greater than or equal to 100 counts per minute (cpm) per $100 \mathrm{~cm}^{2}$ above the background rate. ${ }^{25}$ If $100 \mathrm{cpm}$ per $100 \mathrm{~cm}^{2}$ is the clean-up criteria for material dispersed by an RDD, the clean-up area could be enormous even for a small source. If we consider the uniform dispersal (an impossible task) of a Curie of activity, the result would be the clean up of an area of about 220 square kilometers! ${ }^{26}$ Even cleanup to a level of $10,000 \mathrm{cpm}$ per $100 \mathrm{~cm}^{2}$ would require an area of 2.2 square kilometers to be cleaned up!

What would be the dose resulting from this level of contamination? If we were to consider the $100 \mathrm{cpm}$ to be coming from a point source, this would be the equivalent of $1.67 \mathrm{~Bq}$ source. If we were further to consider that a person received a constant whole body dose from 10 of these sources at a distance of $1 \mathrm{ft}$ and that the source energy was 1 $\mathrm{MeV}$, then by Equation 3 above, the dose rate would be about $2.7 \times 10^{-9} \mathrm{rem} / \mathrm{hr}$ or an annual dose of about $2.4 \times 10^{-5}$ rem per year, a fairly small dose even if increased by a factor of 100. As a general rule-of-thumb, some consider that a $100 \mathrm{cpm}$ above background rate in surveying for contamination will equate to a field strength of 0.01 $\mathrm{mR} / \mathrm{hr}$, which would yield an annual dose of about $88 \times 10^{-3}$ rem year, considerably higher than our calculation, but still on the order of the overall background dose received by the general public. If we were to allow 1,000 times the level of contamination and if the $100 \mathrm{cpm}$ rate corresponds to the $0.01 \mathrm{mR} / \mathrm{Hr}$ rate, the annual dose for 24-hour-a-day exposure would be 8.8 rem, about twice the 5 rem per year allowed for radiation workers.

\footnotetext{
${ }^{22}$ As discussed briefly in a previous section, LNT modeling assumes that whatever injuries (typically cancers per units of population) are observed in high-dose situations (such as Hiroshima and Nagasaki) project in a linear manner to the zero dose level. Thus, if a dose of 200 rem per person results in $\mathrm{x}$ cancers per 10,000 persons, a dose of 0.2 rem will result in $\mathrm{x} / 1000$ cancers for the same population.

${ }^{23}$ The LNT hypothesis allows for the calculation of additional cancers for any given release or exposure by using simple ratios. Whether this effect is real (e.g., defining an area where 1 additional cancer per 10,000 people will occur), or even relevant for planning or evaluation purposes is an open issue in dealing with RWs.

${ }^{24}$ The following rough calculations are recognized to be in error since they simplistically assume that, for example, radioactive materials can be uniformly spread, that all material on a surface can be removed with a swipe, and $100 \%$ detection efficiency.

${ }^{25}$ Although one might think that a dose rate would be more appropriate, many of the survey meters used to measure activity are calibrated in counts per minute. Dose is a more difficult measurement to make.

${ }^{26} 100 \mathrm{cpm}$ is 1.67 counts per second. A Curie of activity is $3.7 \times 10^{10}$ decays $/ \mathrm{sec}$, and $100 \mathrm{~cm}^{2}$ is $10^{-8} \mathrm{~km}^{2}$. Thus, a Curie spread uniformly and $100 \%$ detectable would cover $2.2 \times 10^{10}$ areas of $100 \mathrm{~cm}^{2}$, or about 220 square kilometers.
} 
The important point to recognize is that current clean-up criteria are based on essentially a policy of attempting to clean to a level in which there will be no additional risk. The doses associated with such clean-up standards are indeed very low. As will be discussed further below, for most RWs the most severe impact will be the disruption and economic consequences caused by contamination. How severe these consequences are depend directly on what cleanup is required. Whether what we consider to be contaminated in a peacetime controlled environment is applicable to dealing with contamination spread by an RDD for the purpose of inflicting economic damage is something that will be discussed further below.

\section{Definitions}

What importance, if any, should be associated with definitions? To the extent that definitions establish a common terminology to discuss effects, such issues are obviously of more than academic interest, but that is probably not of great import. However, if the definitions are used to determine which agencies have responsibility for dealing with RWs, the impact of the definition can be great. If variations in definitions lead to fragmentation of responsibilities among agencies, the results can be dangerous.

\section{Existing Definitions}

The term radiological weapon (RW) is a broad term used by a number of authors and agencies without specific definition. At times it used as a synonym for radiological dispersal device (RDD), but as we have seen, and will see, RW is a far broader term.

There are several agencies that have defined what is generally the same item, a RDD. Some define the item as a "radioactive dispersal device," but most use the term "radiological dispersal device." For example, the Department of Energy's National Nuclear Security Administration defines a radioactive dispersal device as:

Any device that is intended to spread radioactive material. An improvised nuclear device can also be an RDD if the explosion does not cause a nuclear yield, but "fizzles," spreading radioactive materials. (U.S. Department of Energy 2001)

The Department of Defense defines an RDD as:

Any device, including weapon or equipment, other than a nuclear explosive device, specifically designed to employ radioactive material by disseminating it to cause destruction, damage, or injury by means of the radiation produced by the decay of such material. (Ford -)

Other definitions tie an RDD explicitly to use of conventional explosives. Sample legislation has been developed for state government for laws related to weapons of mass 
destruction. $^{27}$ Vermont has adopted this code and punishes the use of nuclear or radiological agents which are defined as:

Any improvised nuclear device (IND) which is any explosive device designed to cause a nuclear yield, any radiological dispersal device (RDD) which is any explosive device utilized to spread radioactive material, or a simple radiological dispersal device (SRDD) which is any container designed to release radiological material as a weapon without an explosion. (Vermont Statutes - , emphasis added)

Thus an RDD is far more than a "dirty bomb" mixture of explosives and radioactive material. The broader definitions would encompass, for example, the physical spreading of material by aircraft and by hand. It would also include the contamination of water supplies, foods, crops, and farm animals.

Are the differences in these various definitions of an RDD important? Arguments can certainly be made on both sides of the issue. However, since an RDD is only one example of an RW, it can be argued that by focusing on the definition of an RDD, agencies may be limiting their focus too significantly.

\section{A Proposed Definition of Radiological Weapon}

A problem with many of the definitions of an RDD is that they may be too specific. In general, they deal only with the spread of radioactive materials. Is the removal of a source and placement in a public area to injure people by exposure an RDD? Is an attack on a nuclear power plant an RDD?

None of these examples fits within the definition of an RDD. However, they are examples of the broader definition of a RW, a term whose definition should encompass any use of radiation to injure persons or property. What we have classically thought of as an RDD is some subset, albeit an important subset, of an RW. A straw man definition of an RW is:

An RW is any device or method, except for a nuclear yield-producing device, that uses, or intends to use, radiation from the decay of radioactive materials to cause injury to persons or property by unlicensed exposure.

Under this definition, overexposure with a dental x-ray unit or in a linear accelerator would be excluded, but intentional use of radioactive material to injure, whether or not the material was dispersed would be included.

Is it important to have a new definition to deal with bureaucratically? Of course not. However, some governmental unit should have the charter to consider all the issues dealing with RWs' to coordinate efforts to prevent their use, including development of

${ }^{27}$ Council of State Governments Suggested State Legislation - Terrorism Prevention. 
methods to detect and mitigate the use of such weapons; and to control and coordinate immediate and long-term response to incidents where an RW has been used. Arguably no agency of the government currently has a reach that broad. Should tasks be transferred among agencies so that such a system exists? Would it make sense for the new Homeland Security Department to control security requirements and studies at nuclear power plants? Perhaps it would and perhaps it would not, but whatever bureaucratic alignment may result, at some level there must be meticulous preplanning and a system (multi- or single agency) ready to effect a national response to the use of an RW.

\section{Steps To Acquire And Use Radiological Weapons}

A terrorist or subnational group ${ }^{28}$ that has decided to use an $\mathrm{RW}^{29}$ is faced with a number of issues that must be resolved. It is not clear whether there is a rational order in which the issues appear, or, even if there were, if any group would consider them in a rational manner. However, some or all of the following issues must be dealt with either explicitly or implicitly to employ an $\mathrm{RW}^{30}$ :

- Obtaining radioactive material.

- Selecting a target.

- Determining the level of personal risk or exposure to the "group."

- Operational security measure to prevent intervention.

- Moving materials or a device to the selected target.

- Triggering the RW.

- Post-deployment matters, such as taking credit for the incident and escape.

Intelligence methods could be employed to detect some of these steps, but one thing is clear: If the group or individual could be prevented from obtaining access to radioactive materials, there would be no credible threat. Denial of access to radioactive material, along with detection and interdiction of movement of the material or RW to a target, has been the focus of efforts to upgrade defenses against the use of RWs. Upgrading security screening of users of radioactive materials is another method of denial of access, and there are considerations of how security screening could be implemented in a meaningful manner.

How successful can such methods be? Is there a danger that uniformed reactions to the threat of RWs or the actual use of an RW will cause the loss of flexibility in the use of radioactive materials by taking restrictions too far? These issues will be considered

\footnotetext{
${ }^{28}$ It is important not to have preconceived notions of what a "group" would look like. It might be Osama Bin Laden and his al-Qaida followers, but it could also be only one person. The ideological orientation could cover a broad spectrum from the deeply religious to the criminally insane or the disaffected employee bent on personal revenge.

${ }^{29}$ The psychological aspects of using an RW will not be addressed in this paper. Whether there are significant psychological barriers after September 11 is an interesting issue, albeit one not addressed herein. ${ }^{30}$ Some or all of the following steps might be absent if the purpose of the "group" is not to actually employ the RW, but to extort, cause panic, seek attention, or any of the other myriad of reasons that might cause a group to feign the use of RWs.
} 
further after a discussion of the types of radioactive materials available, the current security procedures, and the hazards of various RWs.

\section{Radioactive Materials Available For Use In A Radiological Weapon}

For an RW there must be radiation and the terrorist or subnational group must either obtain radioactive material or develop a plan where some act or actions (e.g., an attack on a nuclear reactor) put them in contact with a source of radioactive material. We tend to think that theft is the primary method of obtaining radioactive materials for an RW, but assistance by an entity (state-sponsored terrorism for example) or purchase of radioactive materials and/or devices containing them through legal or illegal channels are also possible. Because theft is such a concern, it is important to understand which radioactive materials currently circulate in our environment.

\section{Materials Found In Sources And Industrial Equipment}

The vast majority of the radioactive materials available for use in the world today are manmade. Except for those radioactive materials produced by the detonation of nuclear weapons, manmade radioactive materials are produced in significant quantities only by nuclear reactors or accelerators. This manmade reserve of radioactive material represents the bulk of the material available as a potential source for a radiological weapon.

Natural radioactive materials might also be used in an RW. However, most natural radioactive material (except, for example, concentrated elements like radium) does not have specific activity levels high enough to allow the natural radioactive material to be used in a meaningful way in an RW without significant further processing and concentration.

Fortunately, the combination of half-life and decay energy available in the range of radioactive materials produced in a reactor results in only a few isotopes that are commercially useful. The same criteria that make these radioactive materials commercially useful, relatively long half-life (on the order of years and tens of years) and useful decay energies, also make them attractive for an RW. These characteristics, coupled with the fact that these materials are generally those in the devices subject to theft, mean that there are relatively few radioactive materials that are potential sources for an RW. Table 1 lists the most common isotopes and their characteristics.

Some of the isotopes in Table 1 are generally only found in certain types of applications whereas others, such as ${ }^{137} \mathrm{Cs}$ and ${ }^{60} \mathrm{Co}$, are so useful that they are used in many types of devices. 
Table 1: Isotopes commonly used in sealed radioactive sources. *

\begin{tabular}{|l|l|l|l|}
\hline Isotope & Physical Form & Half-life & Emission \\
\hline Cesium-137 (Cs-137) & Solid (powder) & 30.1 years & $\begin{array}{l}\text { beta } \\
\text { gamma }\end{array}$ \\
\hline Cobalt-60 (Co-60) & Solid (metal) & 5.3 years & $\begin{array}{l}\text { beta } \\
\text { gamma }\end{array}$ \\
\hline Iridium-192 (Ir-192) & Solid & 74 days & $\begin{array}{l}\text { beta } \\
\text { gamma }\end{array}$ \\
\hline Krypton-85 (Kr-85) & Gas & 10.8 years & $\begin{array}{l}\text { beta } \\
\text { gamma }\end{array}$ \\
\hline Radium-226 (Ra-226) & Solid & 1600 years & $\begin{array}{l}\text { alpha } \\
\text { gamma }\end{array}$ \\
\hline Strontium-90 (Sr-90) & Solid & 28.8 years & beta \\
\hline
\end{tabular}

*(Ferguson et al. 2003, p. 9)

The risks associated with various commercial devices that use radioactive materials have been studied by the IAEA. The IAEA has categorized the sources into three categories based on the IAEA's assessment of the hazard posed by the source. Under the IAEA ranking system, Category 1 devices are the most dangerous. The sources are shown in Table 2 where the type of device, typical activity strength for that type of device, and a dose rate at 1 meter from an unshielded source is presented based on the highest source strength for that device. 
Table 2: IAEA Categorization of Radiation Sources by Risk Categories*

\section{Category 1}

\begin{tabular}{|c|c|c|c|c|c|}
\hline $\begin{array}{c}\text { Practice } \\
\text { or application }\end{array}$ & Radionuclide & $\begin{array}{c}\text { Decay } \\
\text { energy [keV] } \\
\text { half-life }\end{array}$ & $\begin{array}{l}\text { Typical } \\
\text { activity }\end{array}$ & $\begin{array}{c}\text { Dose rate at } \\
1 \mathrm{~m}^{\mathrm{a}, \mathrm{b}, \mathrm{c}} \\
{[\mathrm{mSV} / \mathrm{h}]}\end{array}$ & $\begin{array}{c}\text { Time at } \\
1 \mathrm{~m}^{\mathrm{a}, \mathrm{b}, \mathrm{c}} \\
\text { to exceed } \\
1 \mathrm{mSv}\end{array}$ \\
\hline Teletherapy & $\begin{array}{l}\text { Co-60 } \\
\text { Cs-137 }\end{array}$ & $\begin{array}{l}\gamma(1173 ; 1333) \\
\beta(\max .: 318) \\
\mathrm{T}_{1 / 2}=5.3 \mathrm{a} \\
\gamma(662) \\
\beta(\max .: 512) \\
\mathrm{e}(624) \\
\mathrm{T}_{1 / 2}=30 \mathrm{a}\end{array}$ & $\begin{array}{l}50-400 \mathrm{TBq} \\
500 \mathrm{TBq}\end{array}$ & $\begin{array}{l}8 \mathrm{E}+04 \\
3 \mathrm{E}+04\end{array}$ & $\begin{array}{l}<1 \mathrm{~s} \\
<1 \mathrm{~s}\end{array}$ \\
\hline Blood irradiation & Cs-137 & $\begin{array}{l}\gamma(662) \\
\beta(\max .: 512) \\
\mathrm{e}(624) \\
\mathrm{T}_{1 / 2}=30 \mathrm{a}\end{array}$ & $2-100 \mathrm{TBq}$ & $6 \mathrm{E}+03$ & $<1 \mathrm{~s}$ \\
\hline $\begin{array}{l}\text { Industrial } \\
\text { Radiography }\end{array}$ & $\begin{array}{l}\text { Ir-192 } \\
\text { Co-60 } \\
(\mathrm{Cs}-137) \\
(\text { rare }) \\
\\
(\text { Tm-170) } \\
\text { (rare) }\end{array}$ & $\begin{array}{l}\gamma(317) \\
\beta(\max .: 675) \\
\mathrm{e}(303) \\
\mathrm{T}_{1 / 2}=74 \mathrm{~d} \\
\gamma(1173 ; 1333) \\
\beta(\max .: 318) \\
\mathrm{T}_{1 / 2}=5.3 \mathrm{a} \\
\gamma(662) \\
\beta(\max .: 512) \\
\mathrm{e}(624) \\
\mathrm{T}_{1 / 2}=30 \mathrm{a} \\
\gamma(84) \\
\beta(\max .: 968) \\
\mathrm{T}_{1 / 2}=129 \mathrm{~d}\end{array}$ & $0.1-4 \mathrm{TBq}$ & $4 \mathrm{E}+02$ & $9 \mathrm{~s}$ \\
\hline $\begin{array}{l}\text { Sterilization and } \\
\text { food preservation } \\
\text { (Irradiators) }\end{array}$ & $\begin{array}{l}\text { Co-60 } \\
\text { Cs-137 }\end{array}$ & $\begin{array}{l}\gamma(1173 ; 1333) \\
\beta(\max .: 318) \\
\mathrm{T}_{1 / 2}=5.3 \mathrm{a} \\
\gamma(662) \\
\beta(\max .: 512) \\
\mathrm{e}(624) \\
\mathrm{T}_{1 / 2}=30 \mathrm{a}\end{array}$ & $\begin{array}{l}0.1-400 \mathrm{PBq} \\
0.1-400 \mathrm{PBq}\end{array}$ & $\begin{array}{l}1 \mathrm{E}+08 \\
2 \mathrm{E}+07\end{array}$ & $\begin{array}{l}<1 \mathrm{~s} \\
<1 \mathrm{~s}\end{array}$ \\
\hline Other Irradiators & $\begin{array}{l}\text { Co-60 } \\
\text { (Cs-137) } \\
\text { (rare) }\end{array}$ & $\begin{array}{l}\gamma(1173 ; 1333) \\
\beta(\max .: 318) \\
\mathrm{T}_{1 / 2}=5.3 \mathrm{a} \\
\gamma(662) \\
\beta(\max .: 512) \\
\mathrm{e}(624) \\
\mathrm{T}_{1 / 2}=30 \mathrm{a}\end{array}$ & $1-1000 \mathrm{TBq}$ & $3 \mathrm{E}+05$ & $\begin{array}{l}<1 \mathrm{~s} \\
<1 \mathrm{~s}\end{array}$ \\
\hline
\end{tabular}




\section{Category 2}

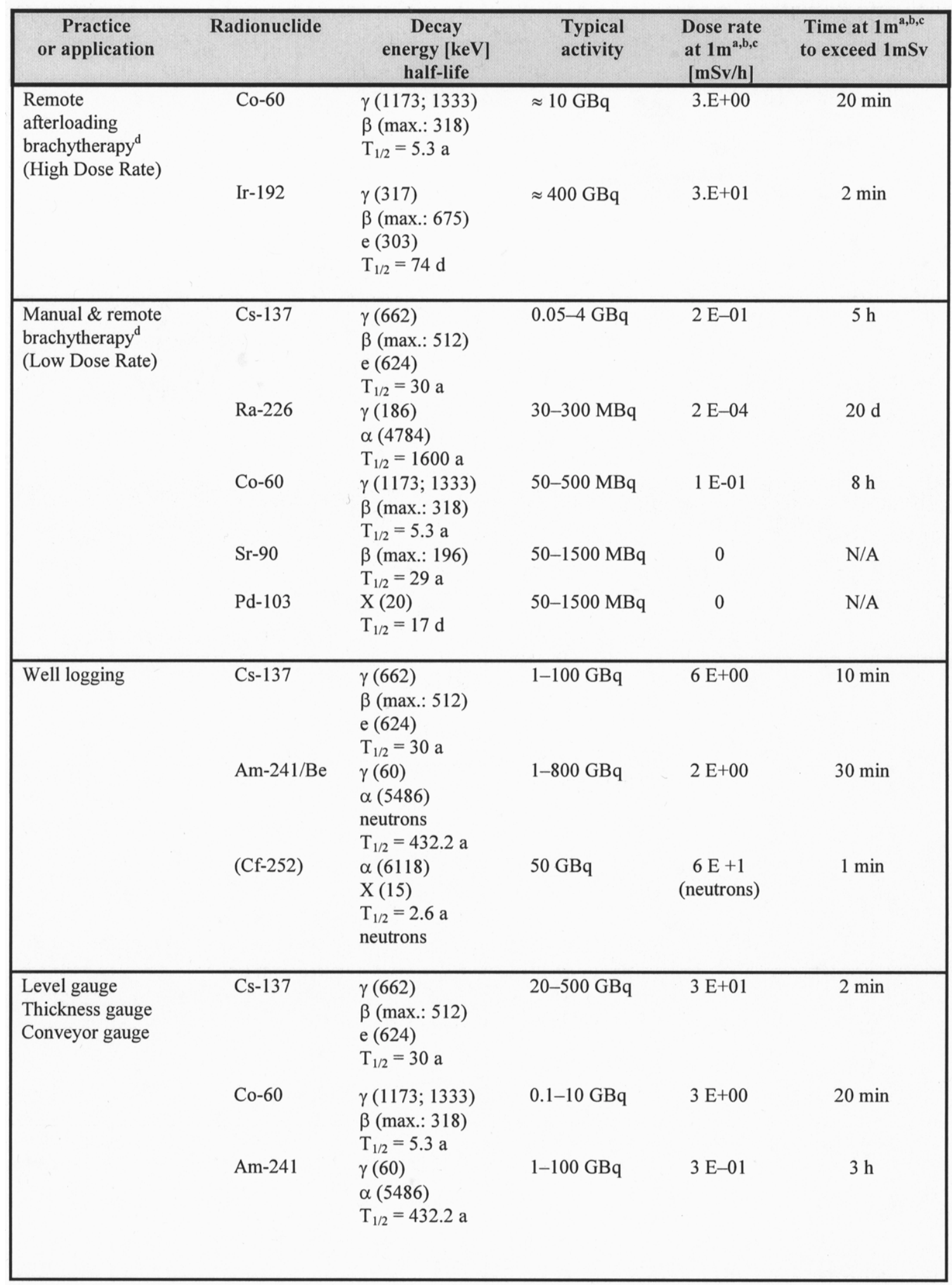




\begin{tabular}{|c|c|c|c|c|c|}
\hline $\begin{array}{c}\text { Practice } \\
\text { or application }\end{array}$ & Radionuclide & $\begin{array}{c}\text { Decay } \\
\text { energy }[\mathrm{keV}] \\
\text { half-life }\end{array}$ & $\begin{array}{l}\text { Typical } \\
\text { activity }\end{array}$ & $\begin{array}{l}\text { Dose rate } \\
\text { at } 1 \mathrm{~m}^{\mathrm{a}, \mathrm{b}, \mathrm{c}} \\
{[\mathrm{mSv} / \mathrm{h}]}\end{array}$ & $\begin{array}{l}\text { Time at } 1 \mathrm{~m}^{\mathrm{a}, \mathrm{b}, \mathrm{c}} \\
\text { to exceed } 1 \mathrm{mSv}\end{array}$ \\
\hline \multirow[t]{4}{*}{$\begin{array}{l}\text { Moisture/density } \\
\text { detector }\end{array}$} & $\mathrm{Am}-241 / \mathrm{Be}$ & $\begin{array}{l}\gamma(60) \\
\alpha(5486) \\
\text { neutrons } \\
\mathrm{T}_{1 / 2}=432.2 \mathrm{a}\end{array}$ & $0.1-2 \mathrm{GBq}$ & $6 \mathrm{E}-03$ & $7 \mathrm{~d}$ \\
\hline & Cs-137 & $\begin{array}{l}\gamma(662) \\
\beta(\max .: 512) \\
\mathrm{e}(624) \\
\mathrm{T}_{12}=30 \mathrm{a}\end{array}$ & to $400 \mathrm{MBq}$ & $2 \mathrm{E}-02$ & $2 d$ \\
\hline & (Cf-252) & $\begin{array}{l}\alpha(6118) \\
X(15) \\
T_{1 / 2}=2.6 \mathrm{a} \\
\text { neutrons }\end{array}$ & $3 \mathrm{G} \mathrm{Bq}$ & $4 \mathrm{E}+00$ & $15 \mathrm{~min}$ \\
\hline & $(\mathrm{Ra}-226 / \mathrm{Be})$ & $\begin{array}{l}\gamma(60) \\
\alpha(5486) \\
\mathrm{T}_{1 / 2}=432.2 \mathrm{a} \\
\text { neutrons }\end{array}$ & $\sim 1500 \mathrm{MBq}$ & & \\
\hline
\end{tabular}

\section{Category 3}

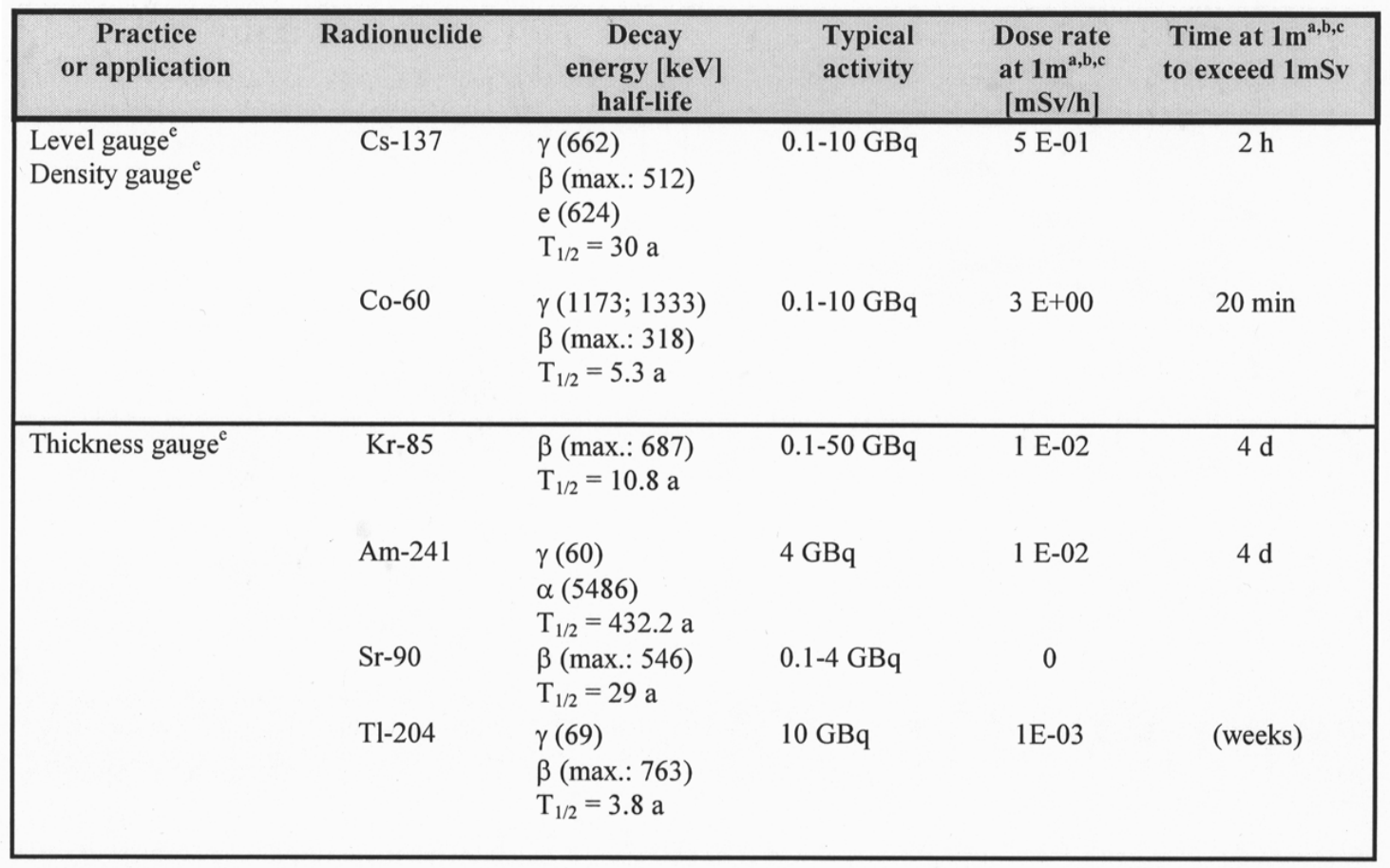

Notes:

a Gamma dose rates were calculated assuming total loss of shielding and upper value of the activity applies.

b Bremsstrahlung radiation was not taken into account.

c Times were calculated assuming total loss of shielding.

d The deliberate exposure of patients in medical applications was not considered in this categorization. Should this be included, and given the likelihood and magnitude of unplanned exposures, brachytherapy would belong to Category 1 , if a comprehensive assessment is not made and a complex set of preventive measures (including a comprehensive quality assurance programme) are not implemented.

e Practices similar to Category 2; lower activity sources generally used.

IAEA-TECDOC 2000) 
As part of their recent study of the risks of commercial radioactive the Monterey Institute took abstracts from Table 2 and converted the activity levels from Becquerels to Curies. (Ferguson et al. 2003, pp. 13-14)

The Monterey Institute's analogous table also includes radioisotope thermoelectric generators (RTGs) in Category 1, listing a strontium 90 source strength of $1.11 \mathrm{PBq}$ to 11.1 PBq. (Ferguson et al. 2003, p. 13) The RTGs are also powered by ${ }^{238} \mathrm{Pu}$ and are used in a number of applications, some of which involve leaving them unattended in remote areas. $^{31}$

There are obviously a great many other single purpose or medically useful radioactive materials and devices, but Tables 1 and 2 capture the common spectrum of devices and materials. For planning purposes in defending against RWs or dealing with exposure or cleanup, the relatively limited number of common isotopes should allow significant research and planning to be directed at specific isotopes.

\section{Materials Found In Reactors And Reactor Related Operations}

There are a number of types of reactors operating in the world today. In addition to commercial power reactors, there are weapons production reactors, research reactors, military propulsion reactors, and small power reactors designed to be used in space.

While unirradiated fuel for a reactor could be used in a radiological weapon, the low activity level associated with the material generally prevents its use. Fuel in an operating reactor (even one that is shut down) contains an enormous inventory of radioactive material, primarily the radioactive fission fragments. Spent fuel is highly radioactive. ${ }^{32}$ Once fuel has been removed after use, the fission fragments and induced radiation remain. Depending on the location of the reactor, some spent fuel may be kept in storage pools at the reactor site or may be shipped to reprocessing or burial sites.

\section{Materials Found In Radioactive Material Disposal Sites}

Throughout the world, there are numerous radioactive material dumps or disposal sites. Some of these are secure facilities with storage inventories and controls. Others are simply burial sites, sometimes, particularly in the states of the former Soviet Union, on facilities that have been abandoned.

\footnotetext{
${ }^{31}$ Although these sources are typically listed as pure alpha or beta emitters, they can generate a considerable penetrating x-ray dose that results from Bremstrahlung interaction with the device's shielding. Alpha emitters can produce a significant number of neutrons via an $(\alpha, n)$ reaction on available oxygen.

32 To get some idea of the inventory of fission fragments in a reactor, it is useful to note that the complete fissioning of 1 kilogram of fissile material produces a yield of about 18 kilotons - about the yield of the Nagasaki bomb. A reactor burns about 1 gram of fissile material per Megawatt (MW) day of power. Therefore a 1,000-MW electrical reactor (typical current size), which is about 3,000-MW thermal burns about 3 kilograms of fissile material per day and makes about three times the fission products of a Nagasaki-size bomb each day. Thus, the long-lived fission products produced in a reactor grow at an almost constant level on a daily basis once a balance between creation and burnup has been established.
} 


\section{Orphaned Sources}

Abandonment of radioactive sources has become such a widespread phenomena that the term "orphan" is now commonly used to describe a radioactive source that is no longer under any control structure. The IAEA has a significant program to assist countries (primarily in the Former Soviet Union (FSU)) in locating orphaned sources and in establishing control and accountability programs.

Disposal costs for proper disposal of radioactive materials can be quite high. Recognizing that there were many sources being stored but no longer used, the DOE established a domestic source recovery program that has recovered thousands of sources. ${ }^{33}$

\section{Depleted Uranium}

Depleted uranium is uranium that remains after uranium 235 has been extracted in an enrichment process. It is primarily uranium 238 and therefore is often referred to as D-38, which resembles higher density lead. D-38 has recently received a great deal of attention in health and nuclear circles due to its widespread use in munitions during the Dessert Storm operations in Kuwait and Iraq and subsequent claims that the spread of D38 in the Gulf caused various cancers and other illnesses among war veterans and the local population.

D-38 is used in a wide number of commercial applications. For example, a Boeing 747 contains hundreds of kilograms of D-38 in counterweights and might have tonnes if heavily ballasted. Uranium 238 is slightly radioactive, and aged D-38 will exhibit the various radioactive characteristics found in the uranium 238 decay chain. Should every aircraft accident now be considered a radiation accident? ${ }^{34}$

\section{Domestic Security of Radioactive Materials}

Whereas the security of nuclear materials for use in a nuclear-yield device has long been a subject of concern, as have security aspects of nuclear reactors, the security of materials outside reactors has received little attention until relatively recently.

At the federal level, the Nuclear Regulatory Commission (NRC) has the primary responsibility for the licensing radioactive sources. The key regulations are set forth in The Code of Federal Regulations (CFR), Title 10, Energy, at 10 CFR 20.1001 et seq. In addition, there are other regulations of the NRC and Department of Transportation that

\footnotetext{
${ }^{33}$ Los Alamos National Laboratory operates DOE's Radioactive Source Recovery Project. It has recovered over 3,000 sources of americium 241, plutonium 238 and plutonium 239. See, http://www.astro.org/public/DOESourceRecovery.html.

34 The crash of an El-Al 747 cargo plane into an apartment complex in Amsterdam, Netherlands, in 1992 has raised a number of issues about the health effects of D-38 use in aircraft.
} 
cover some aspects of handling and shipping various types of sources. (See, for example, 10 CFR 39.1 et seq. re-use of sources for well logging.)

The federal government has delegated its licensing control over radioactive materials to some state governments by means of specific agreements with each of the states. These states are known as "Agreement States" and have agreed to implement federal requirements (such as 10 CFR 20).

The licensing and regulatory regime was created to minimize the exposure from radioactive materials that might occur due to improper usage or from accidents in the storage, use, and transport of radioactive material. There was little consideration given to intentional misuse of materials to harm people or property. Thus, for example, great emphasis is put on making it readily apparent that radioactive material is present wherever the material is located. Signs and placards on the devices using radioactive materials, on the storage facilities for the materials and on vehicles carrying and temporarily storing radioactive materials are hallmarks of the regulatory programs. These notices identifying the presence of nuclear material are classically at odds with the desire to keep the locations of these materials secret from would-be thieves or terrorists. This is a fundamental dilemma and needs thoughtful consideration.

Since virtually every device that contains radioactive material emits some radiation even when the device is not being used, rules governing licensing are designed to separate people and workers from sources of radiation to the greatest extent possible. Often this goal is also at odds with a desire to enhance security. Thus, radioactive sources at temporary job sites are likely to be found in a less secure, unoccupied, parked vehicle instead of, for example, in a more secure occupied construction trailer where the occupants would receive a small additional exposure from the radioactive material.

It would not be inaccurate to say that the regulations that govern the use of radioactive materials are somewhat complex and difficult to deal with. The type of radioactive material is an important consideration, and the regulations are fraught with tables and cross-references that must be understood in order to ensure compliance. The storage and security of sources are generally based on the level of radiation the source emits in its storage mode and concerns for fire safety and for minimizing exposure to humans.

This paper is not intended to be a complex regulatory review, but it is significant to note that the regulations are generally not based on the amount of radioactive material in these devices but on the dose received outside the device's shield. Therefore, regulations are the same over a fairly significant range of activities.

Regulations do, however, require marking high and very high radiation areas. (See 10 CFR 20.1601). A very high radiation area is defined as one where a person could receive an exposure greater than 500 rads at a distance of 1 meter over a 1-hour period. The 500rad-per-hour dose rate is one where a person would receive a fatal dose in about an hour of exposure. It is also important to understand that there is a threshold level set by the 
exemption levels found in Appendix C of 10 CFR 20 below which labeling of radioactive materials is not required.

The regulations are not very specific about storage security. The references are not specific about how security is to be accomplished. For example, 10 CFR $§ 20.1801$ states:

The licensee shall secure from unauthorized removal or access licensed materials that are stored in controlled or unrestricted areas.

Security in storage can generally be met by having a locked facility with key control and with an emphasis on separation from occupied areas and on minimizing entry for health, as opposed to security, reasons. Security criteria for temporary job sites are somewhat less stringent. Devices are generally required to be locked in or to vehicles with locking systems on the device to prevent exposure by unintended operation of the device. Thus, a pickup truck with a device chained to the truck in a locked case would appear to meet all current security requirements. Current security regulations do not appear to call for any type of intrusion or security alarms for storage or usage locations. Alarms and monitors for systems such as large medical sources used for cancer therapy are not for the protection of the source against theft, but are for the prevention of inadvertent exposure.

Regulations also require inventory, leak testing for sealed sources, and reporting procedures for lost or stolen sources. However, the period of inventory checking is relatively long. Since inventory intervals are rather long, items could be missing for months prior to discovery by inventory, and, although rapid reporting of theft or loss is required, there may be discretion in delaying loss or theft reports based on an assessment of risk as determined by the licensee.

Many of these regulatory concerns are currently under review in legislation introduced in the Senate and House by Senator Clinton (NY) and Representative Markey (Mass). The Dirty Bomb Prevention Act of $2002^{35}$ would amend the Atomic Energy Act of 1954 to provide increased security for small sources.

The U.S. domestic procedures are similar to those in Europe and Japan and to the written procedures in many other areas of the world. How well those written procedures are implemented and the actual levels of security are considered questionable in a number of geographic areas.

\footnotetext{
${ }^{35} \mathrm{~S} .350$ is a proposed bill that amends the Atomic Energy Act of 1954 "to strengthen the security of sensitive radioactive material." In essence the legislation would establish an ongoing task force comprised of cabinet level officers such as the Secretary of Defense and theAttorney General, who would recommend appropriate classifications of materials and security measures and meet on an annual basis to update their recommendations.
} 


\section{Effects Of Radiological Weapons}

This section addresses the hazards posed by several types of RWs. The emphasis is not on an exact determination of the effects of any particular type of RW, but rather on the relative lethality and the implications that the hazards of the various types of RWs have on planning for prevention and dealing with an RW event.

\section{RDD}

As noted above, an RDD can encompass more than the explosive driven idea of a "dirty bomb." Intentional mechanical spreading by airplane, by hand, and by mail would also constitute an RDD. Since the effectiveness of an RDD depends on the ability to disperse a material that will cause or threaten harm to people or will disrupt the use of property, we can see that from a practical viewpoint radioactive materials with half-lives shorter than several days would be of very limited value because the effect of the materials would quickly disappear due to their short half-life. Thus, although any use of short-lived medical isotopes in an RDD might cause harm, the number of people who would be exposed is probably limited. ${ }^{36}$

Conversely, radioactive materials with very long half-lives are not very effective in injuring people since the specific activity is very low. Large amounts of the material would be required to cause significant injury to people and significant resources would be needed to disperse the materials.

Numerous groups have rendered predictions about the effects of RDDs. These predictions have focused on urban areas. Figure 1 is taken from one of the scenarios presented to the Senate Committee on Foreign Relations. (Kelly 2002) The scenario is one of the dispersal of a ${ }^{60} \mathrm{Co}$ source from a food irradiation plant by an explosion at the lower tip of Manhattan. These are indeed frightening results, and the conclusions are often quoted when the media consider the hazards of RDDs. Conclusions of such a dire nature depend on several key assumptions of questionable validity. First, they assume that an explosion will create a source term that will distribute the ${ }^{60} \mathrm{Co}$ in a manner that can be input to a weather model. Second, they assume that the number of cancers induced can be predicted by the simple calculation of the amount of dose created in an area using the Linear No Threshold (LNT) model discussed above. Finally, they assume that current EPA cleanup standards would be applied.

\footnotetext{
${ }^{36}$ Thus, the same choices of half-life that make radioactive materials good for commercial devices make them good choices for RDDs and RWs. However, planting a short-lived source of high intensity in a high traffic area could create a dangerously lethal RW and the hazard of short-lived radioisotopes cannot be totally ignored.
} 


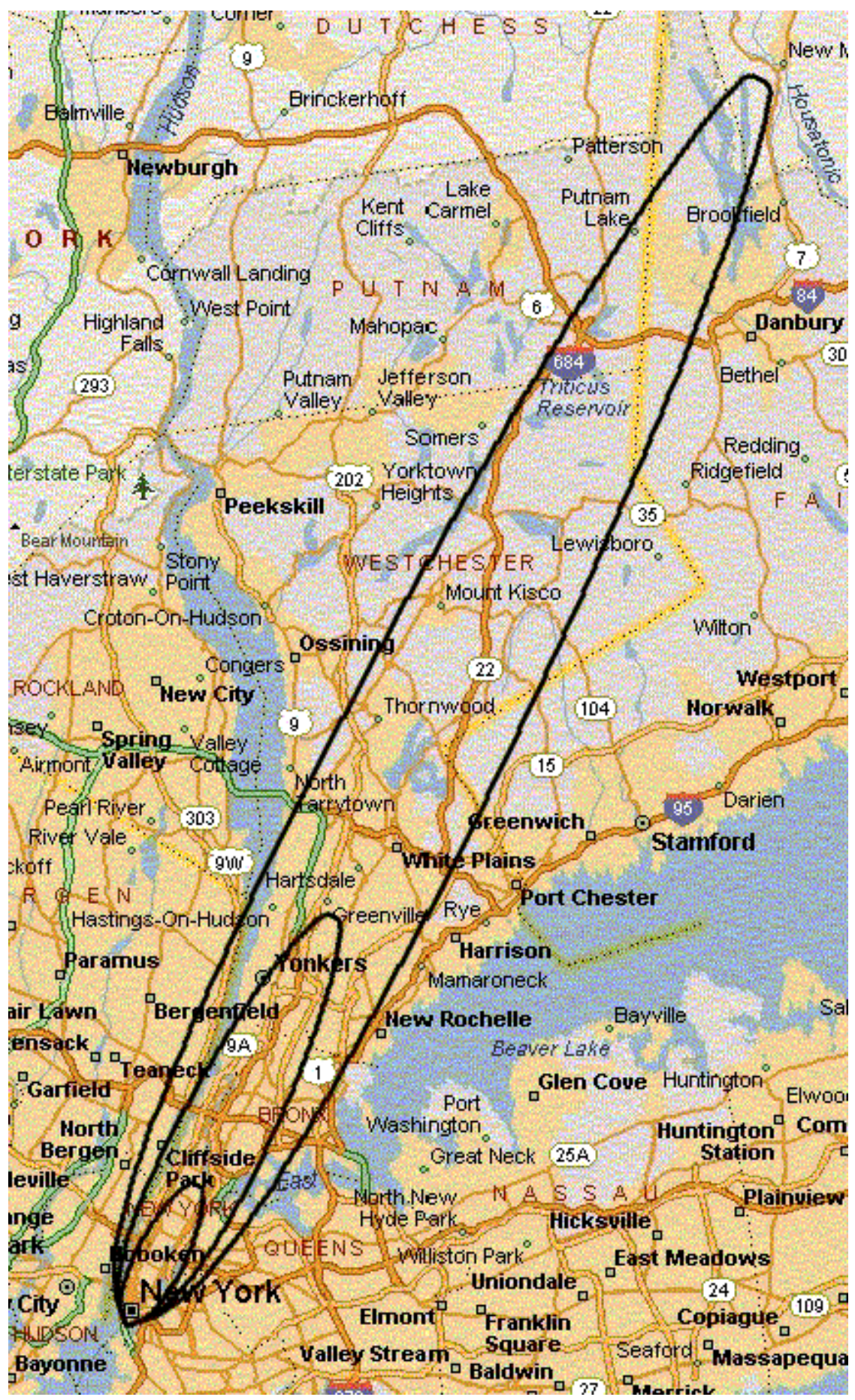

Figure 1: Long-term Contamination Due to Cobalt Bomb in New York City- EPA Standards *

Inner Ring: One Cancer death per 100 people due to remaining radiation.

Middle Ring: One Cancer death per 1,000 people due to remaining radiation.

Outer Ring: One Cancer death per 10,000 people due to remaining

*(Kelly 2002)

radiation.EPA recommends decontamination or destruction 
It is apparently very unclear what the effect of a detonation of explosives would be on radioactive material. Obviously, to some extent, it depends on the physical form of the material, whether the material is left in its shielding, the quality and amount of explosive material, and how the explosives are mated to the material. Forensic investigations of bombings often include a reconstruction of the timing device because the components, contrary to popular expectations, are scattered virtually intact. It may be that if some of the encapsulation of the radioactive materials were retained the materials might not be dispersed at all, but merely thrown or translated by the explosion. It is possible that the radioactive materials could be recovered intact or in several large pieces. Just as the truck used by Timothy McVey in the Oklahoma City bombing was rapidly identified by the serial number on the axle, even a large explosion might do little to disperse radioactive material other than mechanically ejecting the material.

It appears that little research has been done on explosively driven dispersion, but there are indications that the U.S. and Russia may be conducting trials of this nature. (Hanley $2003)^{37}$ If explosives are not good at dispersing radioactive materials, or some of the radioactive materials that might be used for an RDD, is fire a better dispersal mechanism? This also appears to be an area where there has been little study. ${ }^{38}$

It is significant that none of the RDD scenarios described to the Senate Foreign Relations Committee involves immediate deaths from radiation. It is often said, and possibly correctly, that the only fatalities from an explosively driven RDD would probably be from the explosion itself or from the onset of panic that might result from the fear of the radioactive material. How accurate are the assumptions that underlie the curves setting out "one cancer death" per 100, 100, 10,000 in Figure 1? The answer, even if the dispersions were properly calculated (i.e., the explosive deposited all the materials as assumed), is that these determinations assume that the LNT approximation for low-dose health effects is accurate. Further, as will discussed further, even if the assumptions were accurate, the implementation of a post-event screening medical program might far offset the radiation-induced cancers.

Would or should EPA recommendations for peacetime decontamination or, in the alternative, destruction of buildings apply? Again, this depends on the assumptions used for determining the risk of continued occupancy and the willingness to accept higher doses in the event of a radiological emergency. What about the levels in EPA Protective Action Guides? ${ }^{39}$

If an explosively driven RDD is not a particularly effective method to spread radioactive material, would other methods of dispersal be more effective? Some analysts believe that,

\footnotetext{
${ }^{37}$ In this article, Hanley reports that an unnamed U.S. official indicated that Sandia National Laboratory in New Mexico had been experimenting with basic RDD designs in the past 6 months. The article also describes Russian computer modeling of RDDs.

${ }^{38}$ In the absence of any knowledge of the effectiveness of fire in a dispersal, a rapid-fire suppression response may be one of the best efforts that can be made by first responders to the scene of an RW event.

39 The EPA has developed a set of Protective Action Guides that apply to nuclear incidents. Guidelines indicate evacuation of the general population at 1 rem and relocation at 2 rem.
} 
in order to carry out a significant dispersal (i.e., one that is lethal or nearly lethal) other than by explosion or fire, the perpetrator might be fatally exposed. This is certainly not true. Mechanical dispersal from a shielded truck or aircraft could be very effective, but when we have seen terrorists conduct suicidal bombings, we should no longer discredit scenarios that result in death to the perpetrator unless the dose is so high (e.g., thousands of rads) that the incapacitation of the perpetrators inhibits their ability to carry out their intent.

While contamination of water supplies is often discussed, the insoluble nature of many radioactive materials and the ability to dilute the materials so that the dose rate to a given individual is low, makes such a dispersal ineffective.

In summary, the effect of an RDD is largely economic, and the extent of the economic effect is determined by the contamination level that a society is willing to accept for property. The RDD is, therefore, as many maintain, a weapon of mass disruption, not a weapon of mass destruction.

\section{Reactor Or Fuel Storage Attack}

The Chernobyl incident showed the world a worst-case example of what an extremely effective attack on a reactor facility might achieve. However, the RBMK-1000 reactor at Chernobyl was fairly uniquely susceptible to burning and expelling a large portion of its core. Similar in principle to the much smaller British reactor involved in the Windscale accident, the RBMK-1000 was graphite moderated, and the burning graphite and fuel provided a viable method to disperse literally tons of radioactive material.

Other than an attack by a terrorist team employing knowledgeable destruction of reactor safeguards and reactor components over a fairly lengthy occupancy of the key spaces of a reactor facility, it is difficult to see a dispersal similar to Chernobyl resulting from the attack on a western commercial power reactor. Research reactors, although probably far more susceptible to attack because they have far fewer security and safeguard systems, have far smaller core inventories, and their design generally precludes the failure of reactor systems from providing a dispersal mechanism for the core materials.

Shortly after September 11, there was concern about a large jet crashing into a reactor, but several analyses have pointed to the fact that the reactor's containment building would probably withstand the impact. It should also be pointed out that the piloting skill level required to impact the containment building might be considerably higher than that required to hit the World Trade Center. Relatively lower-speed suicide aircraft in WWII frequently missed ships that were much larger than containment buildings.

Could a USS Cole-style attack or a physical attack followed by the use of explosives cause a reactor accident on a nuclear-powered surface vessel or submarine? This is an area that needs careful analysis. Naval propulsion reactors are much smaller than commercial power reactors and may be less vulnerable to damage. However, the 
demonstrated ability of a terrorist group to bring a significant amount of conventional explosive material next to a ship's hull should not be ignored.

Could a terrorist group gain access to and use an aircraft for a conventional bombing of a nuclear reactor or vessel? Are their other methods of attack that could be carried out by "sleeper" agents or extortion of employees? Such scenarios may seem far-fetched, but September 11 should encourage the consideration of defense against any of the possibilities available to terrorists.

Finally, at almost every power reactor, there exists the on-site storage of spent (burned up) fuel. The spent fuel rods are highly radioactive and have always been considered to be self-protecting because removal of the spent fuel rods from their storage pools without the use of massive shielding would result in lethal radiation doses. Could explosives be emplaced in the storage pool to create a significant dispersal? This is a questionable proposition. Although rupture of the cladding of the fuel rods would release many of the gaseous fission products in the spent rods, there would probably be little driving force to release a significant fraction of the radioactive materials. ${ }^{40}$

The size and weight of the spent fuel rods themselves are inhibiting even if the person attempting to remove them to use in an RDD is suicidal. Could a rod or two be removed from a pool and packed with explosives before a suicidal terrorist was incapacitated? Such a scenario should be carefully studied.

In summary, attacks on reactors probably require far more organization than other RWs, but the inventory of radioactive materials is far greater than anything found elsewhere. The vulnerability of all types of reactors and spent-fuel storage facilities to various attacks, including suicidal attacks, should be carefully studied. Earlier safety studies that did not address current threats should be re-examined.

\section{Attack On A Disposal Site}

Disposal sites come in all sizes and shapes. Most disposal sites provide some security, and the method of disposal usually does not allow easy access to the stored material, making it difficult to create a dispersal from the site. In addition, disposal sites are generally remote enough that a dispersal from a site would not create a significant risk of injury or property damage.

Removal of materials from a site to disperse at a target location is an item of concern particularly when the disposal site is abandoned and removal might be done by unobserved excavation. Although this is considered a problem primarily for disposal in the FSU, there are some water disposal sites used by the United States that should examined to see if modern techniques of underwater recovery would allow the retrieval of materials that might be useful to a terrorist.

\footnotetext{
${ }^{40}$ Most of the gaseous fission products are relatively short-lived and many reside trapped in the fuel material. How much would be released would depend on many factors that are difficult to predict, but little would probably be released unless the driving explosive was massive.
} 


\section{Intentional Irradiation Without Dispersal}

Table 2 in Section $\mathrm{F}$ above shows that there are numerous sources in the IAEA's Category 1 that can deliver dose rates over $1 \mathrm{~Sv}$ or 100 rem per hour at a distance of 1 meter. Such sources are capable of delivery of a fatal dose in about 4 hours of exposure.

In their normal state, these sources are well shielded. If the source and shielding were stolen, the weight of the material plus the shielding would be immense. Many of the sources cannot easily be removed from the shielding. However, even for those that can be removed, the concern for theft has historically been low although thefts and subsequent injuries have occurred. ${ }^{41}$ Similar to spent-fuel rods, the high-dose rates associated with high-activity sources have traditionally been thought to provide protection against theft; like spent fuel rods, the suicide aspect of the current terrorist threat may again force a reevaluation of such thinking.

High-strength sources could be emplaced in a public location such as a movie theater, on a train, cruise ship, or other relatively unguarded location where people congregate and could deliver fatal doses with no notice to the victims. Radiography sources would be particularly well suited for this use because they afford protection to the terrorist until a decision is made to remove the source, open a shutter, or create exposure in the same manner that the device is designed to be operated to deliver radiation.

The suicidal or near-suicidal emplacement of an unshielded high-activity source could prove far more lethal than a radiographic source because the strength of the source is often far higher. The sources in many high-activity devices, if removed from their shielding, are small, easily transportable, and only detectable by radiation detectors.

In summary, the intentional irradiation of unsuspecting victims would probably be far more lethal than any dispersal with an RDD although it would cause little property damage.

\section{Summary Of Effects}

It is apparent that the RDD is capable of creating significant economic damage, but is unlikely to create significant acute or long-term injury to persons. The intentional exposure with a high-activity source can potentially create numbers of acute and longterm injuries, but is generally not damaging to property. Attacks on reactors and disposal sites although potentially capable of injury are, like RDDs, chiefly of concern due to their

\footnotetext{
${ }^{41}$ There have been several tragic incidents where large sources have caused injuries. Typically, the source has been lost or abandoned, and poor and/or ignorant people have taken the source for its value as scrap metal, usually opening it out of curiosity. In Goiania, Brazil, four people were killed and others injured by a cesium 137 source, and recently villagers in Georgia were injured when they found an abandoned Sovietera RTG.
} 
economic effects but may cause lethal injuries to persons close to the reactor and/or to incident responders.

\section{Programs To Prevent RWs}

What can be done to prevent the terrorist use of RWs? If regulators adopt the attitude that any program must be absolutely failsafe, it will undoubtedly result in Draconian restrictions that severely curtail or eliminate the use of radioactive materials. Although a failsafe program seems a laudable goal, zero risk is not a realistic goal. Although the possibility of misuse of nuclear technology can be minimized, it will always exist. Establishing a program based on an unrealistic goal may result in a program that is more dangerous in the long run because a program that is too focused on prevention may ignore the need to prepare for mitigation. Any prevention program must reflect the global aspects of the threat of radiological weapons, must represent a cost-effective tradeoff between the risks of beneficial usage of nuclear technology and the threat of misuse, and must also provide a realistic program to deal with the actual use of RWs.

The IAEA has begun to develop recommended programs. (Gonzalez 2001) Such programs concentrate on "cradle to grave" tracking of radioactive materials, getting orphaned sources back under control, increased security regarding who handles materials, and increased inventory requirements.

Many countries will undoubtedly view the IAEA methods as insufficient, not because they are not good ideas and good programs, but because the risks of RWs are sufficiently high that countries such as the United States will feel the need to implement more restrictive regulations.

The United States is engaged in significant efforts to aid other nations in preventing illegal trafficking in materials that could be used for a nuclear-yield weapon. These efforts have not been specifically expanded to include RWs, but many of the aspects of what is done to prevent the use of a nuclear-yield device in the United States would also help to prevent the use of RWs. RWs are probably far more detectable than source materials for a nuclear-yield device at border crossings, in shipping, and in the various ways that items can enter the United States. In contrast to the relatively low radiation signature materials of used in nuclear weapons, RWs are "hot" and more easily detectable.

Incorporation of enhancements in security, reporting, access and control of radioactive materials and the additional burdens they create are necessary results of a response to the apparent increase in threat. Although these foreseeable increases in regulations will have an impact on current users of radioactive materials, there must be an acceptance of the fact that the world has changed with regard to the necessary levels of security.

Future production of radioactive sources can be done in ways that would make the radioactive materials far less accessible or useful in an RW. Governmental programs to 
underwrite the cost of removing existing less-secure sources from service and replacing them with more secure sources should be considered.

Increased radiation monitoring by agencies that have heretofore not played a role in monitoring such as the police (who now perform monitoring in selected areas such as New York City) and by, for example, postal employees, needs to be increased. This would have the benefit of potentially locating materials or a device before it could be used, but would also increase the awareness of what materials are now in the environment. Similarly incorporation of radiation sensors into the environment should be done. Smoke detector/radiation detector combinations should be developed and required by building codes and replacement/exchange programs should be developed to speed the widest dissemination of radiation detectors in places where the public gathers.

Finally, one aspect of prevention that is often overlooked is development of an informed public. This would not only aid in heightening the awareness of potentially illegal activities with radioactive materials, but would minimize the risk of panic casualties when an RW is used.

\section{Programs To Minimize The Impact Of A Radiological Weapon}

Preplanned programs to minimize the impact of RW use are vitally necessary in order to protect people and the economy.

\section{Medical Programs}

Medical treatment programs for radiation accidents and nuclear weapons casualties are not new. However, the end of the Cold War, lack of funding, and new generations of medical personnel require an ongoing training program for dealing with medical treatment for exposure and contamination.

In contrast to the large numbers of casualties anticipated from a nuclear-yield device, the treatment numbers from an RW would probably be low, allowing for better levels of treatment on an individual basis. Since only a few radioactive materials are likely to be encountered, programs should be developed to deal with removing these materials from the body both internally and externally. ${ }^{42}$

Exposure standards for an emergency associated with RWs need to be developed and implemented. Use of peacetime standards for treatment would probably flood medical facilities. Emergency workers and medical personnel need standards that apply in such situations both for their own protection and for the treatment of casualties.

Training every emergency doctor and emergency team and crew to deal with RWs may not be either a realistic or desirable goal. Whether rapidly deployable national or regional

\footnotetext{
${ }^{42}$ For example, there has been a recent interest in using "Prussian Blue," ferric hexacyanoferrate, to remove cesium 137 and other radioactive materials from the body. (Wall Street Journal Online 2003).
} 
teams would be best for primary or supplemental treatment should be evaluated, and the appropriate responses funded.

Finally, since the long-term effects of low-dose exposure are not well known or probably ever knowable, a conservative method of post-event medical monitoring should be developed to provide early detection and treatment for those exposed in an RW event.

\section{Decontamination}

Similar to the medical need for predetermining allowable exposure levels, methods for decontamination need to be developed that will work after RWs have been employed. The current EPA clean-up standards may be far too costly in a metropolitan area if the contamination is widespread. However, very little is known about how to deal with contamination in an urban area like Manhattan. Should there be controlled evacuations in response to RWs? What level of contamination will require evacuation, protective procedures, or long-term cleanup? Are we willing to spend what could be tens or hundreds of billions of dollars to lower an uncertain cancer rate of 1 in 1,000 by a factor of 10 ?

More than paper studies are required. Cleaning procedures and materials need to be developed and tested. Is it easier to seal an area by resurfacing and painting than it is to clean the area? Can leaded paints be used to reduce dose from contaminated surfaces or are the risks of using such materials too great?

Are the risks low enough that some combination of occupancy and cleanup could be done at certain levels of contamination? Are there techniques and methods that could prevent the functioning of or minimize the contamination from an RW if one were discovered prior to its use?

Because the primary impact of RWs may be economic and intimately tied to decontamination, these programs need to be well understood and tested.

\section{The Need For Pre-Event Planning For Economic Loss}

Regardless of how well any government deals with the medical and physical response to a radiological weapon, there is a need for preplanning for the economic consequences of such an event. The September 11 experience pointed out some of the problems that need to be addressed.

In one sense the events of September 11 were, except for the severity, conventional events. While no one anticipated the method of the World Trade Center attacks, airlines, property owners, and individuals were able to obtain insurance that operated to offset their losses. Despite insurance, it was obvious that the World Trade Center attack would have overloaded the civil tort system and probably driven the airlines involved into bankruptcy if the September 11 Victims Compensation Fund of 2001 and the Air Transportation Safety and System Stabilization Act had not been implemented. 
In contrast to the World Trade Center incident, most insurance policies have radiation contamination exclusions in property damage coverage, and many, if not most, policies now exclude coverage for terrorist acts. Currently, the only recourse most property owners would have in the event of business disruption or long-term or permanent damage to their property by contamination would be the much-maligned civil tort system. Resort to the civil tort system would undoubtedly involve sordid attempts to find a "deep pocket" to pay for the damages and would result in a tremendous waste of resources.

For the economy to function smoothly there must be federal assurances that losses suffered from an RW can be covered. Federal involvement in anticipation of nuclearrelated damages is not new. The often-maligned Price-Anderson limitations on liability for reactors are an example of prior federal policy making.

\section{The Impact Of The Suicidal Terrorist}

The willingness of some terrorists to die for a cause must be recognized in all considerations regarding RWs. Is death by radiation acceptable to a suicidal terrorist? Whether there is a difference in the willingness to die as a suicide bomber like those seen in Israel, in the Marine Barracks attack in Lebanon, and in the World Trade Center and Pentagon attacks needs to be explored.

Clearly the willingness to suffer high-level exposure or death increases the potential risk that an unshielded source could be used with lethal effect. The self-protection considerations that have always been argued in protection of spent reactor fuel and the theft of high-activity sources may need to be examined and protections upgraded if justified. The idea that the employment of an RW would include a significant lag time between placement and triggering of any device must be re-examined to consider the effect of suicidal intent.

\section{Conclusion}

Radiological weapons are going to be used by some individual or group, if not this year then next year, or at some time in the foreseeable future. A policy of focusing resources solely on prevention of their use would leave any government open to significant economic disruption when the inevitable use occurs. Preplanning can limit the injuries, property damage, and economic losses that might result from the use of an RW. Moreover, a combination of efforts to prevent and to minimize the impact of RWs may significantly discourage potential users.

The dangers from RWs can be dealt with while society continues to enjoy the benefits of nuclear technology that were promised under Atoms for Peace. However, some restructuring of our use of radioactive materials is necessary to ensure that the current and future uses of radioactive materials outweigh the potential disruption caused by misuse of the materials in RWs. 


\section{References}

Ferguson, Charles D., Tahseen Kazi, and Judith Perera, Commercial Radioactive Sources: Surveying the Security Risks, Center for Nonproliferation Studies, Monterey Institute of International Studies, January 2003, pp. 9, 13-14.

Ford, James L., "Radiological Dispersal Devices, Assessing the Transnational Threat," Strategic Forum of the National Defense University Institute for National Strategic Studies available at http://www.disatersrus.org.

Glasstone, Samuel and Philip Dolan, The Effects of Nuclear Weapons, 3rd Edition, U.S. Government Printing Office, 1977.

Gonzalez, Abel J., "Security of Radioactive Sources - The Evolving New International Dimensions," IAEA Bulletin 4, March 4, 2001.

Hanley, Charles J., "U.S., Russia testing effects of 'dirty bombs,"” Associated Press, San Francisco Chronicle, March 15, 2003, p. A4.

IAEA-TECDOC—1191, International Atomic Energy Agency, December 2000, pp. $13-16$.

IAEA Worldatom, “Tightening Security of Radioactive Materials,” December 3, 2002.

Kelly, Dr. Henry, President of the Federation of American Scientists, testimony before the Senate Committee on Foreign Relations, March 6, 2002.

Shapiro, Jacob, Radiation Protection, A Guide for Scientists, Regulators, and Physicians, 4th Ed. Harvard University Press, 2002.

U.S. Department of Energy, National Nuclear Security Administration, Nuclear Terms Handbook 2001, where the bold terms are defined in the source.

Vermont Statutes Section 3501(a) (5).

Wall Street Journal Online, “The Dirty Bomb Blues,” February 4, 2003. 